\title{
Effect of Calcareous Sediments on Hydrogen Evolution Potential of 16Mn Steel in Seawater
}

\author{
Zhiming Gao ${ }^{l, *}$, Xiaoyu Liu ${ }^{l}$, Lijuan Wen $^{2}$, Weiwei Kang ${ }^{1}$ \\ ${ }^{1}$ School of Material Science and Technology, Tianjin University, Tianjin, 30072, China \\ ${ }^{2}$ Technical Support Department, Hainan Nuclear Power Co., Ltd., Changjiang of Hainan Prov., \\ 572733, China \\ *E-mail: gaozhiming@tju.edu.cn
}

doi: $10.20964 / 110403007$

Received: 30 December 2015 / Accepted: 3 February 2016 / Published: 1 March 2016

\begin{abstract}
Effect of calcareous sediments on hydrogen evolution potential which formed under different cathodic protection potentials was investigated in this paper. Electrochemical impedance spectroscopy (EIS), potentiodynamic polarization and hydrogen permeation experiment were carried out to analyze the electrochemical properties of $16 \mathrm{Mn}$ steels covered with different calcareous sediments. The microstructures of different calcareous sediments were obtained by using three-dimensional microscope and scanning electron microscopy (SEM). It is concluded that, hydrogen evolution potentials of $16 \mathrm{Mn}$ steels covered with different calcium deposits shift negatively to different degrees. As pre-polarization potential turns negative, hydrogen evolution potential of $16 \mathrm{Mn}$ steels pre-treated turns negative constantly at first and then turns positive. The hydrogen evolution potential corresponding to pre-polarization potential at $-1.05 \mathrm{~V}$ is the lowest. Corresponding to the change of hydrogen evolution potential, applying pre-polarization ranging from $-0.90 \mathrm{~V}$ to $-1.05 \mathrm{~V}$, the calcareous sediments obtained become thicker and thicker. Embossments of calcareous sediments increase gradually. Until applying the potential at $-1.10 \mathrm{v}$, the calcareous sediments are damaged. Mechanisms of the phenomenon that hydrogen evolution potential shifts negatively are as follows: one factor is the IR drop caused by calcareous sediments. Another factor is the calcareous sediments can hinder the diffusion of $\mathrm{H}_{2}$ to solution and indirectly inhibit the hydrogen evolution reaction.
\end{abstract}

Keywords: calcareous sediments; hydrogen evolution potential; cathodic protection potential; hydrogen permeation current;

\section{$\underline{\text { FULL TEXT }}$}

(C) 2016 The Authors. Published by ESG (www.electrochemsci.org). This article is an open access article distributed under the terms and conditions of the Creative Commons Attribution license (http://creativecommons.org/licenses/by/4.0/). 